\title{
Clinical and laboratory manifestations of the prothrombin gene mutation in women of reproductive age
}

This article was published in the following Dove Press journal: Journal of Blood Medicine

\author{
AP Momot (D) \\ MG Nikolaeva $\mathbb{( D}^{2}$ \\ NN Yasafova (iD ${ }^{3}$ \\ MS Zainulina $\mathbb{I D}^{4}$ \\ KA Momot $\mathbb{D}^{3}$ \\ IA Taranenko (iD) ${ }^{3}$ \\ 'Altai Branch of FSBI, National Research \\ Center for Hematology, Barnaul, Russia; \\ ${ }^{2}$ Obstetrics and Gynecology Department \\ with The Course in Supplementary \\ Vocational Education at FSBI of Higher \\ Education, Altai State Medical University, \\ Barnaul, Russia; ${ }^{3}$ Altai Branch of FSBI, \\ National Research Center for \\ Hematology, Ministry of Healthcare of \\ the Russian Federation, Barnaul, Russia; \\ ${ }^{4}$ Saint Petersburg State-Financed Health \\ Institution, "Maternity Hospital № 6 \\ Named after Professor V.F. Snegirev", \\ Obstetrics, Gynecology and \\ Reproductive Medicine Department, \\ Pavlov First Saint Petersburg State \\ Medical University, Saint Petersburg, \\ Russia
}

Correspondence: AP Momot Altai Branch, FSBI National Research Center for Hematology, Ministry of Healthcare of The Russian Federation, 122-Papanincev Str. apt 28, 65603I, Barnaul, Altai Region, Russia

Tel +73852689800

Email xyzan@yandex.ru
Research objective: To research the association of prothrombin (factor II) activity given the prothrombin G20210A mutation carriage with its clinical manifestations as thrombotic complications.

Materials and methods: A prospective clinical cohort study of 290 women of reproductive age was conducted. Two cohort groups were identified: the study group of 140 patients with prothrombin mutation G20210A genotype and the control group of 150 women with G20210G genotype.

Results: The prothrombin G20210A mutation carriage is associated with the risk of thrombotic complications compared to the wild $\mathrm{G} 20210 \mathrm{G}$ type ( $\mathrm{RR}=17.1 ; p<0.0001)$ and is characterized by thrombosis localized both in the venous $(66.7 \%)$ and arterial $(33.3 \%)$ vascular pools. The threshold value of prothrombin activity (174.8\%) for G20210A genotype was calculated, making it possible to conclusively predict the risk of thrombotic events with the accuracy of $90.4 \%$.

Conclusion: The phenotypic manifestation of the prothrombin G20210A mutation in the form of venous and arterial thromboses in women of reproductive age is associated with a super-threshold increase in prothrombin (factor II) activity, which makes it possible to stratify the patients into the group of high risk of thromboses.

Keywords: prothrombin gene mutation, prothrombin mutation G20210A genotype, venous and arterial thromboses, prothrombin activity

\section{Introduction}

Despite significant advances in clinical practice and pharmacology, thrombotic events of any localization remain the primary cause of deaths and disabilities in developed countries and represent a global medical and social problem. ${ }^{1,2}$ It has been determined that $6-20 \%$ of verified thrombotic events are conditioned by the prothrombin G20210A mutation, ${ }^{3-5}$ which is characterized by autosomal dominant inheritance and manifests itself in replacing the guanine nucleotide $(\mathrm{G})$ with the adenine nucleotide (A) in the 20210 position. Due to increased minor gene expression, the level and activity of prothrombin encoded by the gene can be 1.5-2 times higher than normal. ${ }^{3}$ Prothrombin, or factor II, refers to vitamin K-dependent blood coagulation factors, being the precursor of the key coagulation enzyme, thrombin. ${ }^{6,7}$

Prothrombin G20210A mutation is found in $1-6 \%$ of the population, ${ }^{8,9}$ increasing the risk of venous thrombosis by $2-4 .^{10}$ 
As concluded by experts, heterozygous carriage of the prothrombin G20210A mutation is seen as a "low risk" factor for the development of venous thromboembolic complications (VTECs), ${ }^{11-14}$ establishing the isolated relative risk of thrombotic complications as $\mathrm{OR}=2-3 .{ }^{15,16}$ However, with additional factors, the magnitude of thrombogenic risk varies significantly. It is reported that combined hormonal contraceptives ( $\mathrm{CHCs}$ ) increase the risk of venous thromboembolic complications (VTECs) for prothrombin G20210A mutation carriers by $16,{ }^{17-20}$ and menopausal hormone therapy increases the risk of DVT by $2-4 .{ }^{19,21-23}$ Along with this, a number of authors have shown that the risk of developing VTECs during pregnancy and postpartum in patients with prothrombin G20210A mutation constitutes OR of 3-15, compared to the time outside of pregnancy. ${ }^{24-26}$

Thus, the risk of thrombosis in prothrombin G20210A mutation carriers can be considered cumulative and dependant on temporary (relatively controlled) factors, such as pregnancy and administration of estrogen containing medications. ${ }^{27}$ Nevertheless, despite a statistically significant association between the prothrombin G20210A mutation carriage and the risk of thrombosis in the setting of additional risk factors (administration of CHCs, MHT, and pregnancy), it is not possible to predict the likelihood of thrombotic events.

Earlier, we conducted a research aimed at studying the association between the Leiden mutation laboratory phenotype and the risk of thrombosis in women of reproductive age. ${ }^{28,29}$ The research lasted 9 years and involved dynamic observation of the cohort of $500 \mathrm{FV}$ Leiden G1691A (FVL G1691A) mutation carriers. It was established that in somatically healthy patients genotype FVL G1691A did not have any bearing on the risk of thromboses and was comparable to that in normal zygote patients [RR 1.5; 95\% CI 0.03-76.5; $\mathrm{p}=0.8269]$. With additional risk factors (co-morbid conditions, injuries, CHCs, pregnancy) the risk of VTEC comprised 9.3 [RR 9.3; 95\% CI 4.7-18.5; $<<0.0001]$ against the wild type FVL G1691G patients. At the same time, our study established that it is the degree of factor Va resistance to activated protein C (APC-R) that plays the key role in the manifestation of a thrombotic event in FVL G1691A patients. It was shown that at APC-R $<0.49$ the risk of acute VTEC is 27.5 times greater $[\mathrm{RR}=0.85 ; 95 \% \mathrm{CI}$ $3.554-214.231 ; \mathrm{p}<0.0015]$. We therefore believe that the threshold value APC-R which determines the risk of thromboses can be viewed as a subclinical apparent phenotype of this mutation. At the same time, there are few data regarding the association of the subclinical manifestation of the prothrombin G20210A mutation with the risk of thrombotic events, which determined the purpose of this work.

\section{Objective}

to research the association of prothrombin (factor II) activity given the prothrombin G20210A mutation carriage with its clinical manifestations as thrombotic complications.

\section{Materials and methods}

According to the specified goal, a prospective clinical cohort study of 290 female patients was conducted from 2012 to 2017 based on clinical divisions of the FSBI HE Altai State Medical University of the Ministry of Healthcare of Russian Federation. There were two cohorts: the study group of 140 patients with prothrombin G20210A mutation genotype (mean age $31.2 \pm 4.7$ years) and the control group of 150 women with the wild prothrombin mutation G20210A genotype (average age 32.3 \pm 3.9 years). The groups were comparable in age $(p>0.05)$ and ethnicity: the study group was $92.9 \%$ of the Caucasian race, the control group was $91.9 \%$ of the Caucasian race $(p>0.05)$. The observation period for both groups comprised no less than 6 years.

Study group inclusion criteria:

- female;

- Prothrombin G20210A mutation (GenBank 176930.0009) carriage;

- 18 to 45 years old.

Control group inclusion criteria were the same as for the study group, but the patients were not prothrombin G20210A mutation carriers.

Study group exclusion criteria:

- autoimmune diseases, including antiphospholipid syndrome;

- factor V Leiden mutation (GenBank 612309.0001) carriage;

- decrease in the functional activity of antithrombin III, proteins $\mathrm{C}$ or $\mathrm{S}$.

The study was approved by the local ethics committee of the FSBI HE ASMU MOH Russia (protocol №5 of 06.25.12). In accordance with the recent revision of the 
World Medical Association's Declaration of Helsinki, prior to the study all women granted their informed consent for their biological material to be used.

Presence of prothrombin G21210A mutation was identified by the PCR method using reagents by Litekh company (Russia). The study material was the human genomic DNA isolated from peripheral blood leukocytes. The analysis was based on the real-time polymerase chain reaction method (Real-Time PCR) using competing TagMan probes complementary to the polymorphic DNA sites. In all patients, prothrombin activity was tested using factor II-deficient plasma, Tromborel S reagent and BCS XP automatic coagulometer (Siemens, Germany). Prothrombin activity in the study group patients was tested 3-9 times throughout the period of observation. In case of the VTEC patients, the result prior to thrombosis was considered.

\section{Statistics}

Statistical data processing was performed using the MedCalc Version 17.9.7 statistical software package (license BU556P12YT-BBS55-YAH5M-UBE51). Variation series were checked for normal distribution using the Shapiro-Wilk Wtest. Laboratory values are presented as scatter plots with box plots (box-and-whisker plot). The box plot represents a median (Me) - middle of the sample, shown as a marker on the inside line of each box; interquartile range - interval between the 25 th and 75 th percentiles containing the central $50 \%$ of the sample's observation, shown as a box; the 25 th and 75 th percentiles (the lower and upper quartiles) containing a quarter of the lowest and a quarter of the highest values in the sample, shown as straight lines (whiskers) coming out of the box. The upper whisker stretches from the upper border of the box to the maximal value. The lower whisker goes from the lower border of the box to the minimal value. The scatter plot representing all data points is superimposed on the box plot.

To compare the levels of prothrombin activity in two independent samples, the Mann-Whitney nonparametric statistical U-test was used. To determine the prognostic value of prothrombin activity index for the development of thromboses in prothrombin G20210A mutation carriers, the ROC curve was used, with subsequent AUC calculation.

For qualitative features, the total and relative values were given in percentage; verification of statistical hypotheses on the coincidence of the observed and expected frequencies was performed using the $\chi 2$ criterion and Fisher's exact test. For binary features, the relative risk
(RR) and 95\% confidence interval (95\% CI) were calculated. The critical significance level of discrepancies $(p)$ was defined as $p<0.05$.

\section{Study results}

In accordance with the data obtained from 140 prothrombin G20210A mutation carriers, thrombotic events over a 6-year observation period were recorded in 32 women (22.8\% of 140), while with the wild G20210G type - in 2 (1.3\% of 150) [RR17.1; 95\% CI: 4.2-70.1; $p<0.0001]$.

In the control group, two instances of thrombosis were represented by VTECs in the deep veins of the lower extremities. Both were defined outside of pregnancy: one episode of thrombosis was induced by taking combined hormonal contraceptives $(\mathrm{CHC})$; the other one was induced by locked intramedullary nailing in the settings of a tibial diaphysis fracture (on the 2 nd day of the postoperative period).

In total, 39 episodes of thrombotic events were recorded in 32 patients with prothrombin G20210A mutation: 26 (81.3\% of 32 ) had a single episode of thrombosis; $5(15.6 \%$ of 32) had an episode of rethrombosis; 1 (3.1\% of 32$)$ had two cases of rethrombosis.

Thrombosis structure as per localization is shown in Figure 1.

In $66.7 \%$ (26 of 39 ) instances observed, the thromboses are found to have had venous localization, while the average age of acute thrombosis occurrence was 30.7 \pm 4.3 years. Arterial thromboses in the form of acute myocardial infarction and ischemic stroke were diagnosed in $33.3 \%$ of cases (13 of 39), the average age of patients in that group being $31.8 \pm 3.8$ years. Thus, it can be concluded that the age at which a thrombotic event occurs with

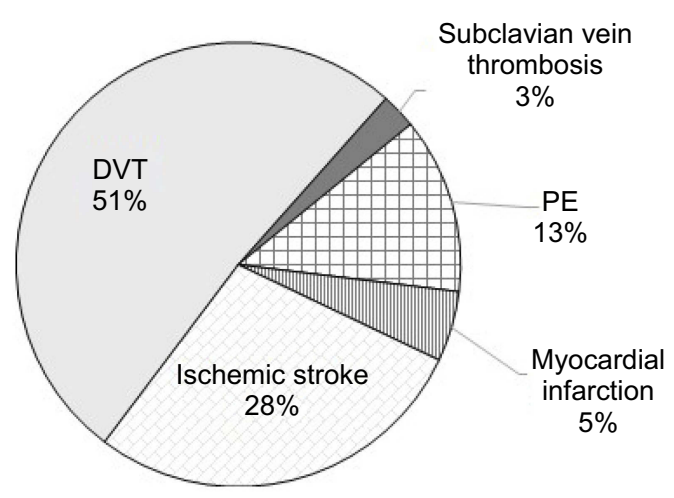

Figure I Thrombosis structure by localization in women (aged 18-45) with the prothrombin G20210A mutation carriage.

Abbreviations: DVT, deep vein thrombosis; PE, pulmonary embolism. 
prothrombin G20210A mutation carriage is comparable $(p>0.05)$ for both arterial and venous localizations.

In order to determine potential risk factors that initiate the development of a thrombotic event, we have carried out a comparative analysis of demographic and clinical history characteristics of patients in both the study and control groups (Table 1).

The analysis has shown that the patients in comparison groups are comparable by age, most of them being 1835 years old. Body Mass Index across the groups was also identical. Extra weight (BMI $>25)$ was found in $27.9 \%$ of prothrombin G20210A mutation carriers and in $24 \%$ of women with the wild prothrombin mutation G20210G type, which does not present any statistical difference. For birth control, CHCs were taken by $20.7 \%$ of women in the study group and $20.0 \%$ of patients in the control group ( $p=0.88), 109(77.9 \%)$ of patients in the group of prothrombin G20210A mutation carriers and 115 (76.7\%) of women in the control group had delivery in history. By delivery parity, there was no statistically significant difference between the comparison group respondents. It is noteworthy that family history burdened with thromboses before 50 years of age in prothrombin G20210A mutation carriers was found in $20.0 \%$ of instances, which is statistically significantly more frequent than in the wild G20210G type group - 4.7\% [OR5.1; 95\%CI 2.2-12.1; $p=0.0002]$.

On the whole, comparative analysis of potential risk factors triggering thrombotic events has shown that the patients in comparison groups are comparable in major parameters analyzed except the family history of thromboses, which suggests inherited predisposition (in our situation, prothrombin G20210A mutation carriage). We were not able to assess the "smoking" factor in comparison groups since some respondents refused to answer this question.

In order to identify potential risk factors triggering thrombotic events in prothrombin G20210A mutation carriers, within the group there was a single factor analysis carried out by specified risk factors (Table 2).

Table I Characteristics of patients in comparison groups

\begin{tabular}{|c|c|c|c|c|c|c|}
\hline \multicolumn{2}{|c|}{ Variable } & \multirow{2}{*}{$\begin{array}{l}\text { Main group G202 I0A geno- } \\
\text { type }(n=140) \\
n(\%)\end{array}$} & \multirow{2}{*}{$\begin{array}{l}\text { Control group G20210G geno- } \\
\text { type }(n=150) \\
n(\%)\end{array}$} & \multicolumn{3}{|c|}{ Statistical values } \\
\hline & & & & OR & $95 \% \mathrm{Cl}$ & $p$ \\
\hline \multirow[t]{2}{*}{ Age } & $18-35$ years & $101(72.1)$ & $112(74.7)$ & 0.9 & $0.5216-1.4801$ & 0.6268 \\
\hline & $>35$ years & $39(27.9)$ & $38(25.3)$ & I.I & $0.6756-1.9171$ & 0.6251 \\
\hline \multicolumn{2}{|c|}{ Caucasian race } & 130 (92.9) & $138(92.0)$ & I.I & $0.4723-2.7057$ & 0.7831 \\
\hline \multirow{5}{*}{$\begin{array}{l}\text { BMI } \\
\left(\mathrm{kg} / \mathrm{m}^{2}\right)\end{array}$} & $<18.5$ & $3(2.1)$ & $2(1.3)$ & 1.6 & $0.2667-9.8449$ & 0.6 \\
\hline & $18.5-25$ & $98(70.0)$ & $112(74.7)$ & 0.8 & $0.4726-1.326$ & 0.3747 \\
\hline & $\geq 25$ & $25(17.9)$ & $30(20.0)$ & 0.6 & $0.4824-1.5674$ & 0.8696 \\
\hline & $\geq 30$ & $8(5.7)$ & $4(2.7)$ & 2.1 & $0.6511-7.5163$ & 0.2033 \\
\hline & $\geq 35$ & $6(4.3)$ & $2(1.3)$ & 3.3 & $0.6575-16.698 \mid$ & 0.1466 \\
\hline \multicolumn{2}{|c|}{ Familial aggregation } & $28(20.0)$ & $7(4.7)$ & 5.1 & $2.1517-12.127 \mid$ & 0.0002 \\
\hline \multicolumn{2}{|c|}{$\begin{array}{l}\text { Patients taking combined } \\
\text { hormonal contraceptives }\end{array}$} & $29(20.7)$ & $30(20.0)$ & 1.0 & $0.5898-1.8516$ & 0.88 \\
\hline \multirow[t]{5}{*}{ Parity } & Nonparous & $31(22.1)$ & $35(23.3)$ & 0.9 & $0.5392-1.6194$ & 0.8091 \\
\hline & Total pregnancies & 316 & 406 & \multicolumn{3}{|c|}{$p>0.5$} \\
\hline & One past delivery & $50(35.7)$ & $59(39.3)$ & 0.9 & $0.5322-1.3796$ & 0.525 \\
\hline & Two past deliveries & $50(35.7)$ & $40(26.7)$ & 1.5 & $0.9262-2.5201$ & 0.097 \\
\hline & $\begin{array}{l}\text { Three or more past } \\
\text { deliveries }\end{array}$ & $9(6.4)$ & $16(10.7)$ & 0.6 & $0.2456-1.348 \mid$ & 0.2032 \\
\hline
\end{tabular}


Table 2 Demographic and clinical history characteristics of patients in the study group depending on the personal thrombotic history

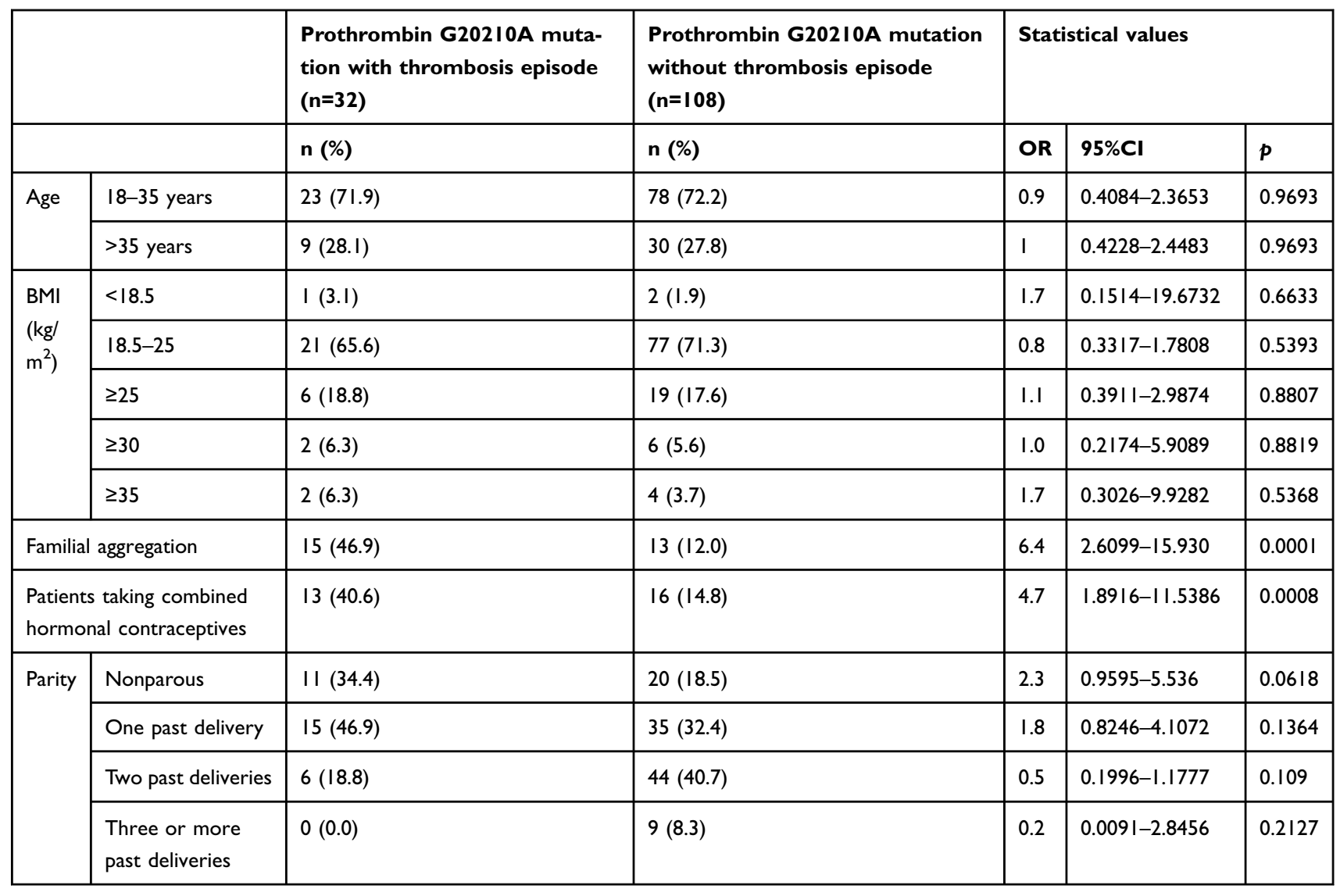

Abbreviation: $\mathrm{CHCs}$, combined hormonal contraceptives.

As per data received, age, BMI, and pregnancy parity have no bearing on the risk of thrombotic events in prothrombin G20210A mutation carriers. Administration of CHCs increases the risk of thromboses more than by 4 times. It has also been found that patients with prothrombin G20210A mutation having family history of thromboses present with personal thrombotic events significantly more often.

Furthermore, we have carried out analysis of clinical situations that initiate the development of a thrombotic event in the analyzed cohort of prothrombin G20210A mutation carriers (Figure 2).

Upon closer examination, it was determined that of 13 (33\%) instances of acute thrombosis occurred in prothrombin G20210A mutation carriers on CHCs, one 39-year-old patient was diagnosed with acute myocardial infarction, and two (24 and 33 years old) with ishemic stroke. Eight studies showed venous thrombosis localization in association with $\mathrm{CHCs}$ in the tibial deep veins (mean age 31.0 \pm 2.4 years), and in two cases PE ( 25 and 39 years old) was diagnosed. In the course of treatment, a cava filter was

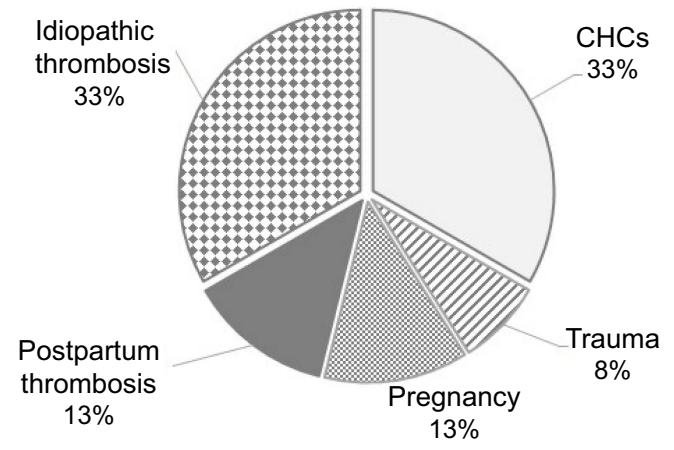

Figure 2 Causative factors preceding thrombotic events in patients of the study group.

implanted in three patients. It should be noted that CHCs were prescribed solely for the purpose of contraception.

During pregnancy, 10 thrombotic events were diagnosed (25.6\% of 39 episodes). In two cases, it was an ischemic stroke diagnosed in the first trimester of pregnancy; in 8 cases, it was thrombosis localized in the lower leg deep vein region that developed in 5 patients 2-3 days after delivery and in 3 patients during the first and second trimester. 
In 13 studies (33.3\% of 39 thrombosis episodes) with prothrombin G20210A mutation carriage, the cause of thrombosis could not be established. In 4 patients with idiopathic acute thrombosis, there was a rethrombosis episode on CHCs during the first year $(\mathrm{n}=2)$ and during pregnancy $(\mathrm{n}=2)$.

Further on, development of thromboses with prothrombin G20210A mutation carriage was juxtaposed with its previous laboratory phenotype. For this purpose, prothrombin activity (factor II) in the study groups was tested. In patients with the wild prothrombin mutation G20210G type, the median (Me) of this factor's coagulation activity was determined as $108.0 \%$ [95\% CI: 103.0-111.2], which is 1.4 times less than in prothrombin G20210A mutation carriers without a thrombosis episode in history - $148.5 \%$ [95\% CI: $145.3-156.9 \%]$. With VTECs $(n=26)$, the median prothrombin activity was $178.2 \%$ [95\% CI: $151.5-$ 190.3\%], and with arterial thrombosis $(n=13)-180.1 \%$ [95\% CI: 172.4-201.3\%]. It was also found that the median prothrombin activity is comparable for venous and arterial thromboses $(p=0.1469)$, and its performance differs significantly from that in women with prothrombin G20210A mutation without a thrombotic episode $(p<0.0001)$ (Figure 3).
Designations: median - marker; box - interval between the 25th and the 75th percentiles containing the central $50 \%$ of excerpt's observations; whiskers - values corresponding to the 25 th and 75 th percentiles.

Taking into account the data obtained, a ROC analysis was performed to determine the critical cut-off threshold for prothrombin activity (\%) to predict the development of thrombosis in prothrombin G20210A mutation carriers regardless of thrombosis localization (Figure 4).

The area under the curve (AUC) of the prothrombin activity index was defined as 0.904 (95\% CI: 0.825-0.955) with the level of significance at $p<0.0001$, which determines good informational content of the analyzed diagnostic method. The maximal diagnostic significance is determined with prothrombin activity at $174.8 \%$ (sensitivity: 81.8 ; specificity: 91.5 ).

\section{Discussion}

During the 6-year observation of the prothrombin G20210A mutation cohort, we recorded thrombosis of both venous (66.7\%) and arterial beds (33.3\%). It should be noted that the evidence base regarding the risk of thrombotic events with heterozygous form of the prothrombin G20210A mutation in previously published documents was determined only

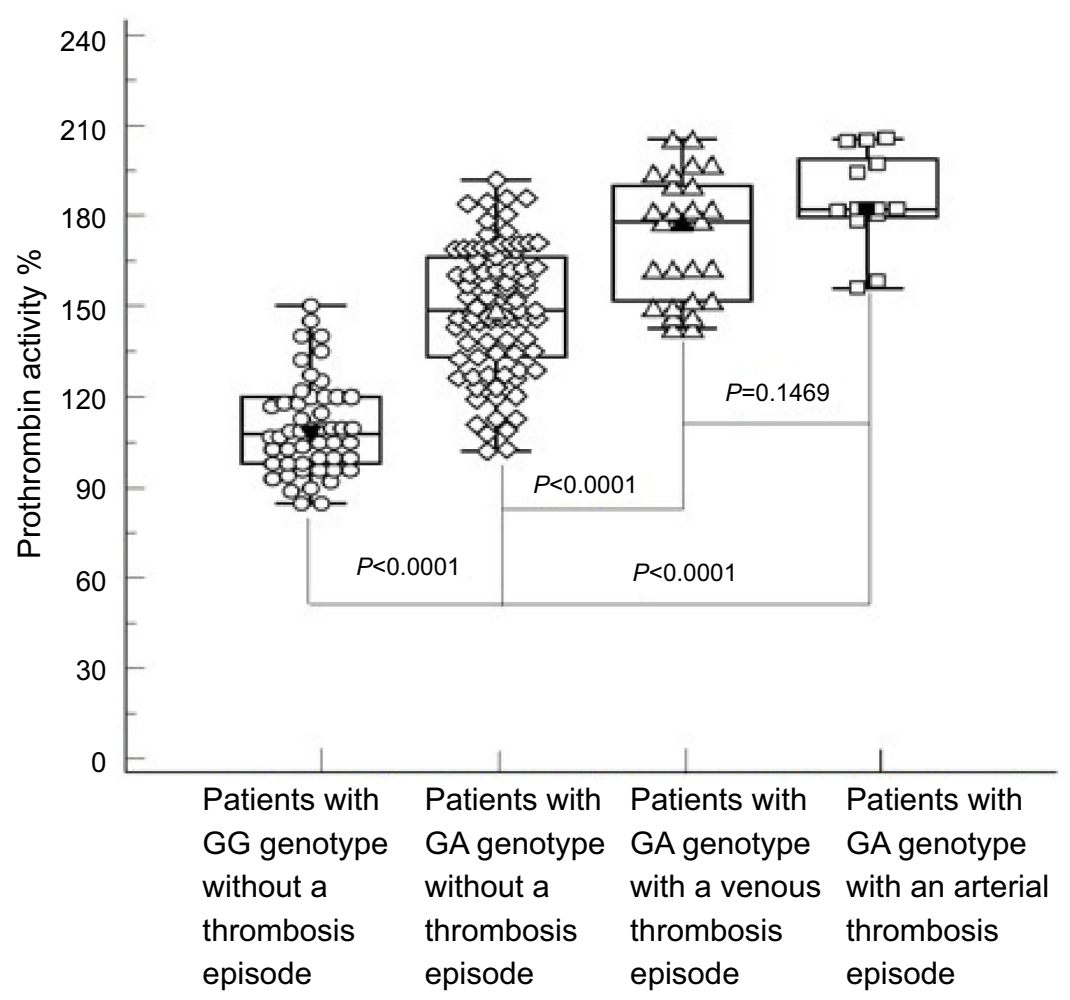

Figure 3 Prothrombin activity indices with and without a thrombotic event in women with prothrombin G202IOA mutation and with the wild G202I0G type. Prothrombin activity medians across the groups were juxtaposed using the Mann-Whitney nonparametric statistical U-test. 


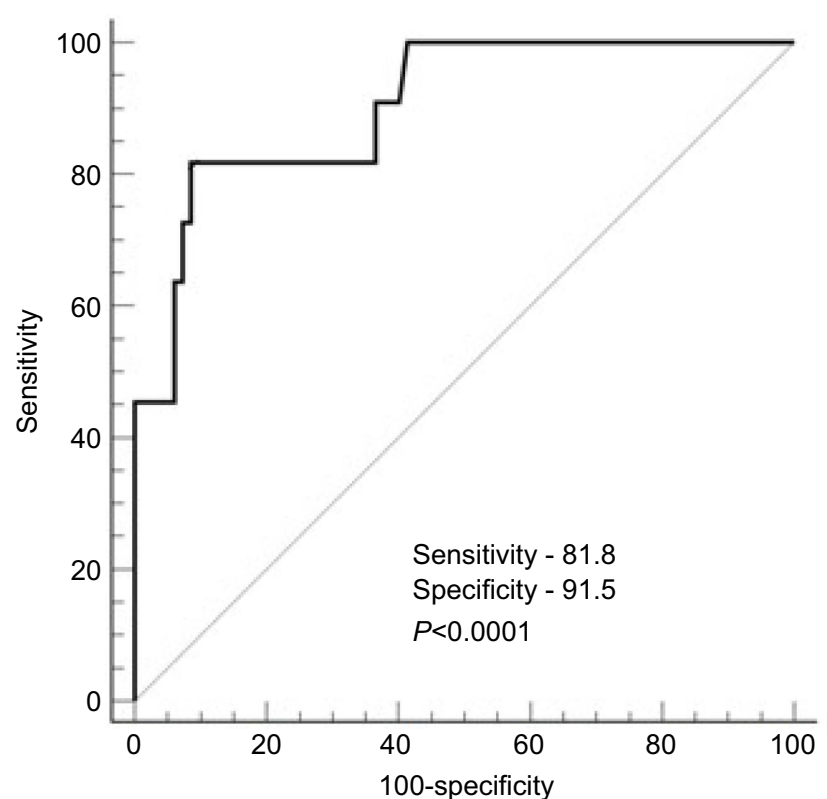

Figure 4 ROC curve model to predict the development of thrombotic events as per prothrombin activity (\%) in prothrombin G20210A mutation carriers.

for thrombosis in the venous basin. ${ }^{2,9,30}$ Nevertheless, in our study, every fourth case of thrombosis is described as an ischemic stroke, and in 5\% of cases myocardial infarction was diagnosed. These data are consistent with the previously published results from other authors, where the prothrombin G20210A mutation is also considered as a proven risk factor for arterial thrombosis in patients under the age of 45: in particular, ischemic stroke (OR 1.6; 95\% CI 1.3-2.0) and myocardial infarction (OR 2.6; 95\% CI 1.1-6.3). ${ }^{31-36}$

It is known that the prothrombin G20210A mutation is a key risk factor for thrombosis; however, the latter is most likely to occur with additional triggers, such as CHCs, pregnancy and trauma. ${ }^{25,32,38,39}$ In the present work, CHCs are defined as an additional factor leading to a thrombotic event in the settings of the prothrombin G20210A mutation. Estrogen-containing drugs are known to be absolutely contraindicated for patients with the prothrombin G20210A mutation. ${ }^{14,37,38}$ Nevertheless, in our study, 29 patients with the prothrombin mutation G20210A genotype were administered estrogen-containing contraceptives, which was clinically manifested as thrombosis in $44.8 \%$ of cases (13 out of 29) during the first month of intake. Taking into account that estrogen-containing drugs are widely used in the gynaecological practice (contraception, menopausal hormone therapy, ovulation induction cycles, etc.), we calculated the risk of thrombosis with CHCs for patients with the prothrombin G20210A mutation as 13.9 [RR 13.9; 95\% CI: 1.9-96.3; $p=0.0097]$. It can be noted that the obtained data do not contradict previous studies. ${ }^{18,20}$

A number of articles have identified the role of pregnancy and the postpartum period in increasing the risk of thrombosis in congenital thrombophilia. ${ }^{25,39}$ In the present work, with prothrombin G20210A mutation the risk of developing thrombosis during pregnancy and the first 6 weeks after delivery is identical and is calculated as 14.1 [RR 14.1; 95\% CI: 0.78-254.47; $p=0.0727$ ], which is consistent with the previously published data.

It is known that both pregnancy ${ }^{40-42}$ and combined oral contraceptives $^{43-45}$ are accompanied by an increase in prothrombin activity in blood plasma. It is likely that the primary increase in this factor (associated with the prothrombin G20210A mutation) in combination with the secondary one (during pregnancy or $\mathrm{CHC}$ administration) is more likely to manifest itself as thrombosis. In our work, the critical threshold value of prothrombin activity was calculated as $174.8 \%$ and higher, which allows, as our analysis has shown, to predict the development of thrombosis in $90.4 \%$ of cases.

\section{Conclusion}

The phenotypic manifestation of the prothrombin G20210A mutation can be considered as two interrelated phenomena: a thrombosis-preceding suprathreshold increase in the activity of prothrombin (Factor II) and thrombosis itself. The significance of our study is primarily seen in highlighting the key role of high prothrombin activity in patients with the prothrombin G20210A mutation. It can serve as an objective laboratory criterion that allows stratification of patients into the group at high risk of thrombosis.

\section{Abbreviation list}

AUC, area under the curve; APCR, activated protein $\mathrm{C}$ resistance; VTECs, venous thromboembolic complications; CHCs, combined hormonal contraceptives; 95\% CI, 95\% confidence interval; DVT, deep vein thrombosis; Me, median; NR, normalized ratio; $p$, the significance level of differences; PE, pulmonary embolism; OR, Odds Ratio; ROC, receiver operating characteristic; RR, Relative Risk.

\section{Disclosure}

The authors declare no conflicts of interest in this work. 


\section{References}

1. Creanga AA, Berg CJ, Syverson C, et al. Pregnancy-related mortality in the United States, 2006-2010. Obstet Gynecol. 2015;125(1):5-12. doi:10.1097/AOG.0000000000000564

2. Royal College of Obstetricians and Gynaecologists (2015) Green-top Guideline No. 37b. Thromboembolic disease in pregnancy and the puerperium: acute management. Available from: https://www.rcog. org.uk/en/guidelines-research-services/guidelines/gtg37b/. Accessed March 1, 2019.

3. Poort SR, Rosendaal FR, Reitsma PH, Bertina RM. A common genetic variant in the 30 -untranslated region of the prothrombin gene is associated with elevated plasma prothrombin levels and an increased in venous thrombosis. Blood. 1996;88:3698-3703.

4. Emmerich J, Rosendaal FR, Cattaneo M, et al. Combined effect of factor V Leiden and prothrombin 20210A on the risk of venous thromboembolism - pooled analysis of 8 casecontrol studies including 2310 cases and 3204 controls. Study group for pooledanalysis in venous thromboembolism. Thromb Haemost. 2001;86(3):809-816.

5. Gehring NH, Frede U, Neu-Yilik G, et al. Increased efficiency of mRNA $3^{\prime}$ end formation: a new genetic mechanism contributing to hereditary thrombophilia. Nat Genet. 2001;28(4):389-392. doi:10.1038/ng578

6. Magnusson S.The Enzymes. 3rd edition. Vol. 3. New York: Academic Press; 1971:277-321.

7. Crawley JT, Zanardelli S, Chion CK, Lane DA. The central role of thrombin in hemostasis. J Thromb Haemost. 2007;5(Suppl 1):95101. doi:10.1111/j.1538-7836.2007.02500.x

8. Spector EB, Grody WW, Matteson CJ, et al. Technical standards and guidelines: venous thromboembolism (Factor $\mathrm{V}$ Leiden and prothrombin 20210G > A testing): a disease-specific supplement to the standards and guidelines for clinical genetics laboratories. Genet Med. 2005;7(6):444-453. doi:10.109701.GIM.0000172641.57755.3A

9. Dziadosz M, Baxi LV. Global prevalence of prothrombin gene mutation G20210A and implications in women's health: a systematic review. Blood Coagul Fibrinolysis. 2016;27(5):481-489. doi:10.1097/MBC.0000000000000562

10. Franco RF, Reitsma PH. Genetic risk factors of venous thrombosis. Hum Genet. 2001;109(4):369-384. doi:10.1007/s004390100593

11. Klein L, Bhardwaj V, Gebara B. Cerebral venous sinus thrombosis in a neonate with homozygous prothrombin G20210A genotype. $J$ Perinatol. 2004;24:797-799. doi:10.1038/sj.jp.7211187

12. Martinelli I, Battaglioli T, Razzari C, Mannucci PM. Type and location of venous thromboembolism in patients with factor $\mathrm{V}$ Leiden or prothrombin G20210A and in those with no thrombophilia. J Thromb Haemost. 2007;5:98-101. doi:10.1111/j.15387836.2006.02291.x

13. Jacobsen AF, Dahm A, Bergrem A, Jacobsen EM, Sandset PM. Risk of venous thrombosis in pregnancy among carriers of the factor $\mathrm{V}$ Leiden and the prothrombin gene G20210A polymorphisms. $J$ Thromb Haemost. 2010;8(11):2443-2449. doi:10.1111/j.15387836.2010.04038.x

14. Nicolaides AN, Fareed J, Kakkar AK, et al. Prevention and treatment of venous thromboembolism. International consensus statement. Int Angiol. 2013;32(2):111-260.

15. Bank I, Libourel EJ, Middeldorp S, et al. Prothrombin 20210A mutation: a mild risk factor for venous thromboembolism but not for arterial thrombotic disease and pregnancy-related complications in a family study. Arch Intern Med. 2004;164:1932-1937. doi:10.1001/archinte.164.17.1932

16. Segal JB, Brotman DJ, Necochea AJ, et al. Predictive value of factor V Leiden and prothrombin G20210A in adults with venous thromboembolism and in family members of those with a mutation: a systematic review. JAMA. 2009;301:2472-2485. doi:10.1001/ jama.2009.853
17. Williamson MA, Snyder LM, Wallach JB. Wallach's Interpretation of Diagnostic Tests. 9th ed. Philadelphia: Wolters Kluwer/Lippincott Williams \& Wilkins Health; 2011.

18. Vandenbroucke JP, Rosing J, Bloemenkamp KW, et al. Oral contraceptives and the risk of venous thrombosis. $N$ Engl $J$ Med. 2001;344:1527-1535. doi:10.1056/NEJM200105173442007

19. Gomes MP, Deitcher SR. Risk of venous thromboembolic disease associated with hormonal contraceptives and hormone replacement therapy: a clinical review. Arch Intern Med. 2004;164(18):19651976. doi:10.1001/archinte.164.18.1965

20. Wu O, Robertson L, Langhorne P, et al. Oral contraceptives, hormone replacement therapy, thrombophilias and risk of venous thromboembolism: a systematic review. The thrombosis: risk and economic assessment of thrombophilia screening (TREATS) Study. Thromb Haemost. 2005;94(1):17-25. doi:10.1160/TH04-11-0759

21. Simone B, De Stefano V, Leoncini E, et al. Risk of venous thromboembolism associated with single and combined effects of factor $\mathrm{V}$ Leiden, prothrombin 20210A and methylenetethraydrofolate reductase C677T: a meta-analysis involving over 11,000 cases and 21,000 controls. Eur J Epidemiol. 2013;28(8):621-647. doi:10.1007/s10654013-9825-8

22. Daly E, Vessey MP, Painter R, Hawkins MM. Case-control study of venous thromboembolism risk in users of hormone replacement therapy. Lancet. 1996;348:1027. doi:10.1016/S0140-6736(96)24041-3

23. Grodstein F, Stampfer MJ, Goldhaber SZ, et al. Prospective study of exogenous hormones and risk of pulmonary embolism in women. Lancet. 1996;348(9033):983-987. doi:10.1016/S0140-6736(96) 07308-4

24. Varga EA, Moll S. Cardiology patient pages. Prothrombin 20210 mutation (factor II mutation). Circulation. 2004;110(3):e15-8. doi:10.1161/01.CIR.0000135582.53444.87

25. Gerhardt A, Scharf RE, Beckmann MW, et al. Prothrombin and factor $\mathrm{V}$ mutations in women with a history of thrombosis during pregnancy and the puerperium. $N$ Engl J Med. 2000;342(6):374-380. doi:10.1056/NEJM200002103420602

26. Martinelli I, De Stefano V, Taioli E, et al. Inherited thrombophilia and first venous thromboembolism during pregnancy and puerperium. Thromb Haemost. 2002;87(5):791-795.

27. Hertzberg MS. Genetic testing for thrombophilia mutations. Semin Thromb Hemost. 2005;31:33-38. doi:10.1055/s-2005-863803

28. Momot AP, Nikolaeva MG, Elykomov VA, Momot KA. The role of APC-resistance for predicting venous thrombosis and pregnancy complicationsin carriers of factor V Leiden (1691) G/A mutation. In: Pregnancy and Birth Outcomes. Intech Open; 2018:33-57. doi:10.5772/intechopen.72210

29. Momot AP, Nikolaeva MG, Zainulina MS. The main causes of thrombotic events in carriage of Leiden mutation in women of reproductive age. J Hematol Thrombo Dis. 2018;6:296. doi:10.4172/23298790.1000296

30. National Institute for Health and Clinical Excellence. Venous Thromboembolism: Reducing the Risk. Reducing the Risk of Venous Thromboembolism (deep Vein Thrombosis and Pulmonary Embolism) in Patients Admitted to Hospital. NICE Clinical Guideline 92. London: NICE; 2010.

31. Rosendaal FR, Siscovick DS, Schwartz SM, et al. A common prothrombin variant $(20210 \mathrm{G}$ to $\mathrm{A})$ increases the risk of myocardial infarction in young women. Blood. 1997;90(5):1747-1750. http:// www.bloodjournal.org/content/90/5/1747.long?sso-checked=true.

32. Reiner AP, Siscovick DS, Rosendaal FR. Hemostatic risk factors and arterial thrombotic disease [review]. Thromb Haemost. 2001;85:584595. doi: $10.1055 / \mathrm{s}-0037-1615638$

33. Casas JP, Hingorani AD, Bautista LE, Sharma P. Meta-analysis of genetic studies in ischemic stroke: thirty-two genes involving approximately 18,000 cases and 58,000 controls. Arch Neurol. 2004;61(11):1652-1661. doi:10.1001/archneur.61.11.1652 
34. Bentley P, Peck G, Smeeth L, Whittaker J, Sharma P. Causal relationship of susceptibility genes to ischemic stroke: comparison to ischemic heart disease and biochemical determinants. PLoS One. 2010;5(2):e9136. doi:10.1371/journal.pone.0009136

35. Korchagin VI, Mironov KO, Dribnokhodova OP, et al. The role of genetic factors in the development of individual predisposition to ischemic stroke. Hum Physiol. 2017;43(8):886-897. doi:10.1134/ S0362119717080047

36. Rallidis LS, Gialeraki A, Tsirebolos G, Tsalavoutas S, Rallidi M, Iliodromitis E. Prothrombotic genetic risk factors in patients with very early ST-segment elevation myocardial infarction. J Thromb Thrombolysis. 2017;44(2):267-273. doi:10.1007/s11239-017-1520-2

37. Bloemenkamp KWM, Rosendaal FR, Helmerhorst FM, Vandenbroucke JP. Higher risk of venous thrombosis during early use of oral contraceptives in women with inherited clotting defects. Arch Intern Med. 2000;160:49-52. doi:10.1001/archinte.160.1.49

38. Medical eligibility criteria for contraceptive use - 3rd ed. World Health Organization; 2004 ISNB 9241562668 (NLM classification: WP 630). Available from: http://bono-esse.ru/blizzard/Gyn/ Contracep/MEC-merged_2004.pdf. Accessed March 1, 2019.

39. Middeldorp S, van Hylckama Vlieg A. Does thrombophilia testing help in the clinical management of patients? $\mathrm{Br} J$ Haematol. 2008;143:321-335. doi:10.1111/j.1365-2141.2008.07339.x
40. Stirllng Y, Woolf I, North WRS, Seghatchian MJ, Meade TW. Haemostasis in normal pregnancy. Thromb Haemost. 1984;52:176-182.

41. Thornton P, Douglas J. Coagulation in pregnancy. Best Pract Res Clin Obstet Gynaecol. 2010;24:339-352. doi:10.1016/j.bpobgyn.2009.11.010

42. Momot AP, Semenova NA, Belozerov DE, Trukhina DA, Kudinova IY. The dynamics of the hemostatic parameters in physiological pregnancy and after delivery. J Hematol Blood Transfus Disord. 2016;3:005. doi:10.18411/d-2016-058

43. The Oral Contraceptive and Hemostasis Study Group. The effects of seven monphasic oral contraceptive regimens on hemostatic variables: conclusions from a large randomised multicenter study. Contraception. 2003;67:173-185. doi:10.1016/S0010-7824(02) 00476-6

44. Brummel-Ziedins KE, Vossen CY, Butenas S, Mann KG, Rosendaal FR. Thrombin generation profiles in deep venous thrombosis. J Thromb Haemost. 2005;3:2497-2505. doi:10.1111/j.1538-7836.2005.01584.x

45. Aldrighi JM, De Campos LS, Eluf Gebara OC, Petta CA, Bahamondes L. Effect of a combined oral contraceptive containing 20 microg ethinyl estradiol and 75 microg gestodene on hemostatic parameters. Gynecol Endocrinol. 2006;22(1):1-4. doi:10.1080/ 09513590500430328

\section{Publish your work in this journal}

The Journal of Blood Medicine is an international, peer-reviewed, open access, online journal publishing laboratory, experimental and clinical aspects of all aspect pertaining to blood based medicine including but not limited to: Transfusion Medicine; Blood collection, Donor issues, Transmittable diseases, and Blood banking logistics; Immunohematology; Artificial and alternative blood based therapeutics; Hematology; Biotechnology/nanotechnology of blood related medicine; Legal aspects of blood medicine; Historical perspectives. The manuscript management system is completely online and includes a very quick and fair peer-review system. Visit http://www.dovepress.com/testimonials.php to read real quotes from published authors. 